\title{
SPEECH TELEPRACTICE: INSTALLING A SPEECH THERAPY UPGRADE FOR THE 21ST CENTURY
}

\author{
MICHAEL P. TOWEY, MA, CCC-SLP, F-ASHA \\ Waldo County General Hospital, Voice \& SWAllowing Center of Maine, Belfast, Maine
}

\section{ABSTRACT}

Much of speech therapy involves the clinician guiding the therapeutic process (e.g., presenting stimuli and eliciting client responses). However, this Brief Communication describes a different approach to speech therapy delivery. Clinicians at Waldo County General Hospital (WCGH) use high definition audio and video to engage clients in telepractice using interactive web-based virtual environments. This technology enables clients and their clinicians to co-create salient treatment activities using authentic materials captured via digital cameras, video and/or curricular materials. Both therapists and clients manipulate the materials and interact online in real-time. The web-based technology engenders highly personalized and engaging activities, such that clients' interactions with these high interest tasks often continue well beyond the therapy sessions.

Keywords: Telepractice, speech therapy

\section{VIDEO CONFERENCING AND WEB-BASED TELEPRACTICE}

The American Speech-Language-Hearing Association (2012b) defines telepractice as "the application of telecommunications technology to delivery of professional services at a distance by linking clinician to client, or clinician to clinician, for assessment, intervention, and/ or consultation (para. 1)." The efficacy of speech therapy delivered via telepractice has been well documented for more than twenty years (ASHA, 2011). The implementation of speech therapy telepractice (ASHA, 2005) is steadily evolving from the use of expensive dedicated video conferencing systems to significantly less expensive hardware and web-based software.

Web-based telepractice for the purpose of this article describes a virtual environment where the clinician and client are connected virtually and interact in real-time through audio and video with authentic images, video, and learning materials. This definition expands upon the traditional interpretation of the term 'web-based', which may be interpreted simply as an Internet-based connection to support video conferencing. Typical use of video conferencing systems for the delivery of speech telepractice consists of the client sitting at a table and viewing the therapist on a video monitor. The interaction often involves the therapist presenting directions to the client to obtain a response. Therapy materials are manipulated and displayed by the therapist (e.g., by holding traditional print materials in front of the camera, or using a document camera to transmit traditional print materials to the client).
In contrast, in a web-based interactive virtual environment (Figure 1), the therapist and client are "virtually" engaged, with each using a computer with a webcam and high speed Internet connection. The therapist and client manipulate materials and make responses "online" in real-time, using high definition video and audio.

Figure 1: A low cost Internet web-based speech telepractice system. Image (C) Michael Towey, 2010

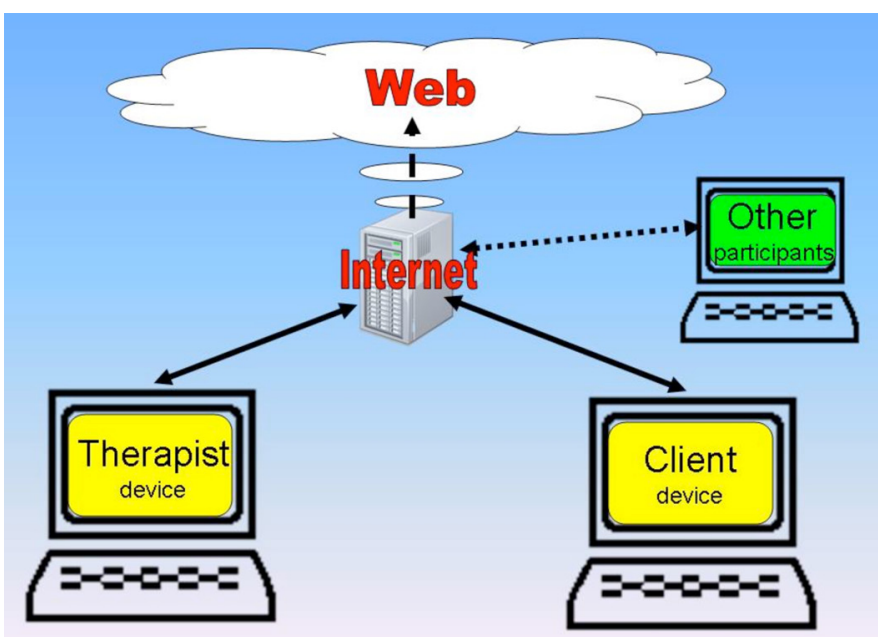


In a comprehensive web-based telepractice system, a variety of electronic annotation/responding tools are available (Figure 2). The client and therapist can therefore co-create treatment plans using authentic materials captured with digital cameras, video, and/or curriculum materials. The client works on specific objectives, often co-developed with the therapist in the virtual sessions.

Figure 2: A screen shot of web-based telepractice that features authentic materials and an array of therapist/ client response tools.

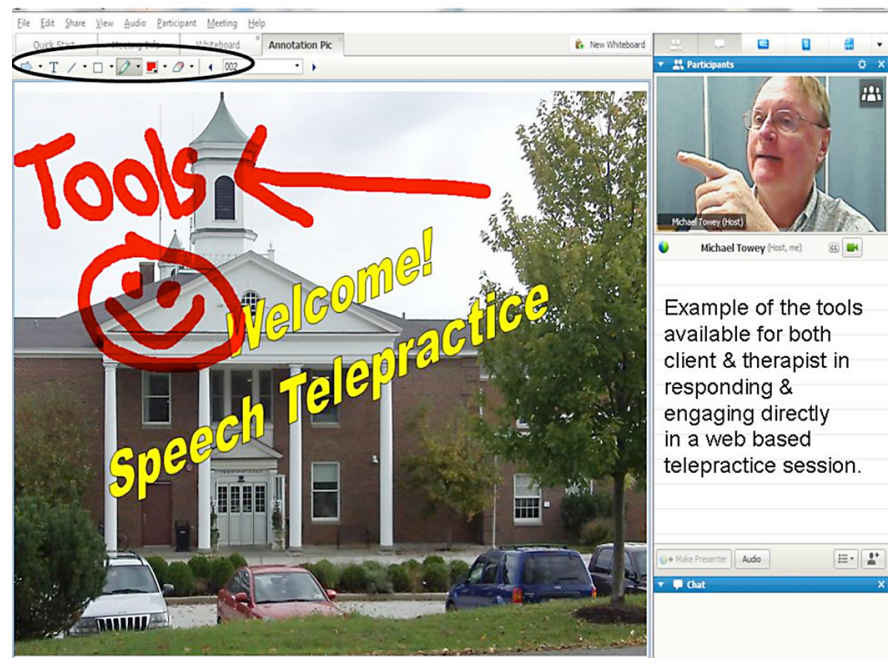

A web-based model allows both the therapist and client to work in online programs in a true digital learning environment (Christensen, Johnson, \& Horn, 2008). Therapy sessions can be recorded, edited, saved and later viewed online by the client, caregivers, family members and/or teachers who are granted access to the materials. The client can go online multiple times to access the therapy program for additional practice and learning. The therapist has the ability to monitor the client's responses to virtual therapeutic materials as often as desired before the next scheduled treatment session.

For example, a client may develop an extended story narrative using available online programs such as Go Animate (2012), Animoto (2012) or Toca Boca (2012), while addressing the therapy goals established by the therapist. The client and therapist create the script using a screen sharing application in the telepractice session, perhaps employing repurposed web-based programs or apps. The session and therapeutic materials can be saved and reviewed multiple times by the client, who can access this authentic treatment session from any laptop, smart phone, or electronic tablet.

Many speech-language practitioners find repurposed web-based programs and apps useful to engage clients and achieve therapeutic outcomes in new ways. There are a number of Internet sites that have a good selection of programs and applications categorized by disorder and treatment application (Kuster, 2010). The dizzying selection of available web-based programs and apps can be simplified using the FIVES criteria described by Sean Sweeney (SpeechTechie, 2012):

- $\quad$ Free/fairly priced

- Interactive

- Visual

- Educationally relevant

- Speechie (i.e., programs that are rich in speech and language and can easily be repurposed for therapy use)

\section{MAKING THE CASE FOR A NEW THERAPY MODEL}

The professional identity of "speech correctionists" has evolved to "speech-language pathologists" and has benefited from a rapidly increasing knowledge base about communicative function. Yet, it is also true the delivery of speech therapy in clinics and schools is much the same today as it was 89 years ago when Smiley Blanton, one of the pioneers in "speech correction" wrote one of the first therapy methods books (Blanton, 1923; Duchan, 2010). The materials have changed somewhat, and the programs are better packaged, but 89 years later, Smiley Blanton would still know where to sit and what to do in most of today's speech therapy rooms. Therapists still sit across the table from the client. Using print materials, they attempt to have the client practice speech skills and somehow hope that new behaviors and skills will be retained. Sometimes therapists use computers and electronic tablets in therapy, but many applications are digitalized versions of the same old familiar pictures and drill cards, analogous to old wine in a new bottle.

Despite the progressive expansion of the profession's knowledge base, an "unavoidable conclusion is that clinicians have little research evidence on which to base decisions about service delivery" (Cirrin et al., 2010, p 248). A recent scholarly review concluded that "service delivery factors do not appear to have a significant effect on speech and language outcomes in children" (Schooling, Venediktov, \& Leech, 2010, p. 24). And often, it is the caseload size that dictates what services the school-aged client receives, not the child's needs (Brandel \& Loeb, 2011). Against this backdrop of equivocal results for traditional treatment, a web-based approach to speech therapy offers a transformational model for influencing communicative behavior. Web based approaches to speech telepractice are closely aligned with the national digital learning initiative (Digital Learning Now, 2012) and the need for individualized instruction to meet individual learning styles (Gardner, 2011).

Today's students are often labeled as bored and unmotivated in school by teachers and parents. Outside 
of school, these same students focus intensely for hours on electronic devices, gaming devices, and social media. Today's students don't seem to lack attention or motivation; instead, they may be bored and uninspired by the instructional materials and approaches used in schools and speech clinics that are unrelated to how they live and learn (Prensky, 2008).

Recognizing that little has changed in almost a century of speech therapy service delivery, speech-language pathologists at Waldo County General Hospital (WCGH) began to develop a web-based telepractice approach. It is exciting to contemplate how a web-based approach might enable clients to go far beyond the therapist's clinical skills, knowledge, and drill cards to succeed in a world that increasingly demands the use of an array of communication and digital literacy skills.

When a web-based telepractice model is used to deliver speech therapy services, clients have numerous opportunities for communicative learning across multiple cycles of interaction throughout the day via computers, smart phones, virtual learning and digital therapy activities. By using web cameras, smartphones, and electronic devices to develop authentic speech therapy treatment, web-based telepractice immerses a client into a fully engaged experience and helps create autonomous learners fully capable of navigating the digital world (Gates, 2010). Our experiences suggest speech therapy telepractice is much more immediate and focused than traditional therapy.

Utilizing a web-based approach requires special clinical competencies. The skilled telepractitioner has mastered competencies that include technical, procedural, interactive, and virtual preparation so as to create an entirely different experience for both the therapist and the client. Speech therapy telepractice via a web-based approach allows therapists to be creative programmers for therapy and to guide clients to create their own authentic content and engage in intrinsically motivated activities, with video, digital pictures, social interactions, and blogs.

For many years, therapists have tried to identify ways to improve "generalization in speech therapy." Therapists are often aware of the need to make therapy activities adequately challenging to match a child's developmental readiness, (i.e., "zone of proximal development") (Vygotsky, 1978), but may rely on games and activities that are too easy. Today's clinical digital age allows for the individualization of therapy materials to create authentic personal treatment objectives that are intrinsically motivating and create the desirable level of difficulty to drive learning and real progress (Christensen, 2008).

\section{CASE EXAMPLES OF WEB-BASED INTERVENTION}

Jeffrey ${ }^{1}$ is a seven year old child with deficits in written language formulation and reading. He is intensely interested in firemen and fire engines. One of our therapists created an online blog for Jeffrey. He uploaded his own pictures and images of fire engines and trucks and wrote about his experiences. The blog was set up to be secure and private, with Jeffrey's mother serving as an eHelper. Each time Jeffrey worked on his blog, his therapist received an alert via an email message. It was then very easy for the therapist to give Jeffrey feedback about his activities and direct him toward his goals. This allowed the therapist to guide this high interest authentic activity for Jeffrey. Jeffrey engaged in this activity multiple times throughout the day, greatly increasing his practice opportunities and achievement of speech therapy objectives.

In another example, WCGH therapists were contacted via the Internet by a woman working in England. Her father had suffered a stroke (i.e., CVA) in rural India and needed speech therapy services. The patient was a fluent English speaker prior to the CVA. WCGH therapists continue to provide therapy to the patient in India, while his daughter participates in the treatment and follow up therapy from England. ${ }^{2}$ He received approximately 20 hours of additional practice each week with his wife and daughter, using the actual therapy activities recorded during the speech telepractice sessions. The patient is now talking in sentences from a baseline of single words, and continues to make good progress. Figure 3 displays a screen shot of the patient (and his wife) in India, his daughter (in England) and the WCGH therapist in Maine, USA, all connected on their personal computers by secure high definition video, and all participating in the treatment session. The biggest challenge for the WCGH therapist was coordinating treatment sessions across three time zones, with at least 12 hours difference.

${ }^{1}$ Name changed to protect anonymity

'Licensure laws and regulations vary by state and country; practitioners must adhere to licensure laws and regulations when engaging in telepractice. 
Figure 3: Connecting from Maine USA to India, more than 11493 kilometers away (7143 miles), with secure high definition web-based speech therapy telepractice on personal computers using no special hardware or software.

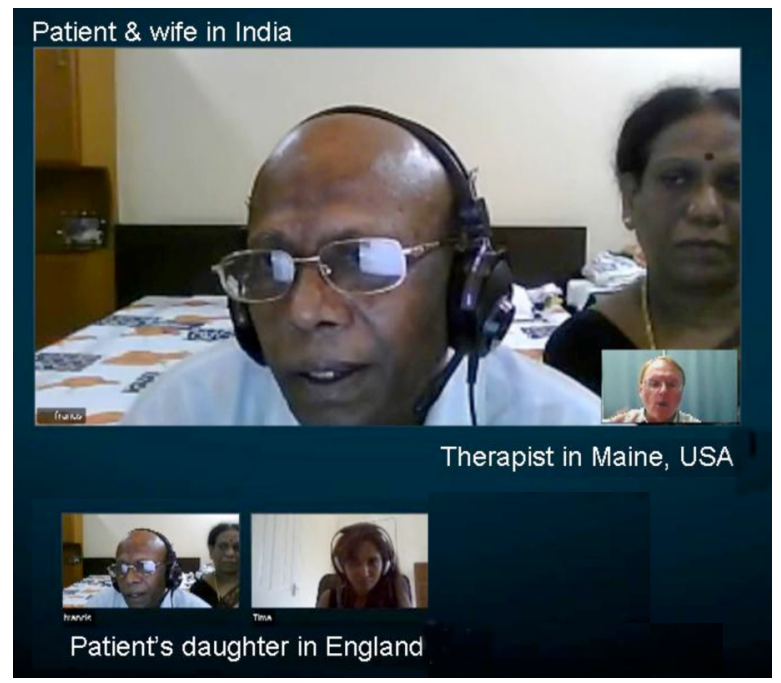

\section{VENDOR SELECTION, CONFIDENTIALITY AND POLICIES}

Web-based telepractice can be inexpensively initiated using easily accessible technology. Requirements include a secure, web-based vendor with a reliable Internet connection and a webcam for both the therapist and client. The therapist can connect to any client who has a computer with similar capabilities.

Confidentiality remains a concern with telepractice that connects with web-based systems. Inherently, web-based video connections are not secure. A system must be encrypted and password protected, and the therapist must be very familiar with how protected health information (PHI) is to be stored and managed in a webbased system. The regulations of both HIPAA and the High Tech Act 2009 have stringent guidelines for security and confidentiality. Some of the most widely used video conference systems lack these secure measures and cannot be used for telepractice.

Speech therapy telepractitioners should have written policies and procedures in place about the confidentiality standards in use; how those standards are reviewed; how any security/confidentiality breech will be managed and reported; and how the client is informed about security and what specific security confidentiality measures are in place.

\section{TELEPRACTICE: A STANDARD OF CARE}

Speech therapy telepractice is emerging as a standard of care that promises to be equal to or better than traditional "table top" therapy. Many people think speech telepractice is only relevant for people in rural areas who have no access to services. The idea of "nothing else is available so let's try telepractice" is giving way to new ways of thinking about the delivery of speech therapy.

A web-based speech therapy telepractice program can be a force multiplier for a speech-language pathologist who works in multiple schools, reducing travel. In one school in a very rural location in western Maine, speech therapy services are provided via telepractice to eight children who were matched up with WCGH therapists. Using the expertise of four different therapists, we provide services to a rural school that previously had difficulty sustaining service delivery. The quality of services and variety of therapists being provided to this rural area exceeds the range of services that might be found even in a large school system or clinical setting.

No longer must therapy be provided solely by the therapist who happens to be scheduled in the school or at a designated location; a therapist with specific expertise can be matched to the children's therapeutic needs. And, children from different schools with similar needs can participate in online groups. These advantages suggest great potential for speech telepractice. 


\section{PRELIMINARY RESULTS}

Table 1 depicts the progress of children who received either in-person "table top" therapy or telepractice speech therapy from the same Waldo County General Hospital (WCGH) therapists. Children who received speech therapy via telepractice achieved the best outcomes, even out-performing the national benchmarks for children from similar diagnostic and demographic backgrounds. These outcomes were derived using three years of cumulative National Outcomes Measurement System (NOMS) Functional Communication Measures data (ASHAa, 2012).

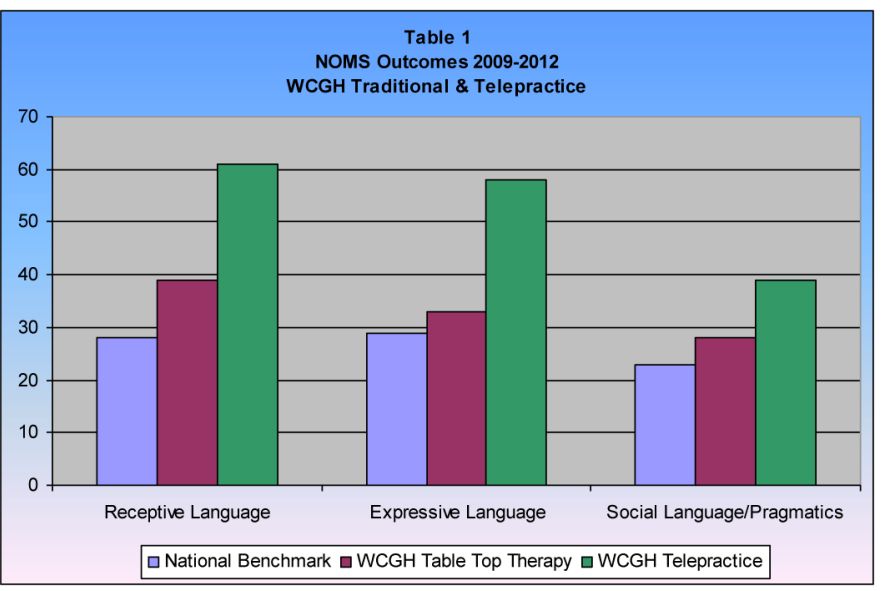

While the participant sample is low $(<150)$, a promising trend is evident. In addition, high rates of web-based telepractice satisfaction were reported by teachers, e-helpers, and parents, consistent with previously published reports (Crutchley \& Campbell, 2010; Curtis, Whitcomb, \& Wilbur, 2011).

\section{SUMMARY}

Speech therapy telepractice, judiciously applied by trained practitioners, is transforming speech therapy delivery. Low cost devices can now be used to provide less expensive quality treatment where people live, learn and work- - anywhere on the planet.

\section{REFERENCES}

1. American Speech-Language-Hearing Association. (2005). Speech-language pathologists providing clinical services via telepractice: Position statement [Position Statement]. doi: 10.1044/policy.PS2005-00116. Retrieved from American Speech-Language-Hearing Association website: http://www.asha.org/docs/html/PS2005-00116. html

2. American Speech-Language-Hearing Association. (2011). Articles about telepractice for speech language pathology and audiology. Retrieved from http://www. asha.org/practice/telepractice/TelepracticeReferences. htm

3. American Speech-Language-Hearing Association. (2012a). National Outcomes Measurement System (NOMS). Retrieved from http://www.asha.org/members/ research/NOMS

4. American Speech-Language-Hearing Association. (2012b). Telepractice for SLPs and audiologists. Retrieved from http://www.asha.org/practice/ telepractice/

5. Animoto. (2012). http://animoto.com

6. Blanton, S. (1923). A speech correction program for the public schools. National Conferences for Social Work

7. Brandel, J., \& Loeb, D.F. (2011). Program intensity and service delivery models in the schools: SLP survey results. Language, Speech, and Hearing Services in Schools, 42, 461-490. doi:10.1044/0161-1461(2011/100019)

8. Christensen, C., Johnson, C., \& Horn, M. (2008) Disrupting class: How disruptive innovation will change the way the world learns. New York: McGraw Hill

9. Cirrin, F., Schooling, T., Nelson, N., Diehl, S. Flynn, P., Staskowski, M...Adamczyk, D. (2010). Evidence based systematic review: Effects of different service models on communication outcomes for elementary school-age children. Language Speech Hearing Services in Schools, 41, 233-264. doi:10.1044/0161-1461(2009/08-0128)

10. Crutchley, S., \& Campbell, M. (2010). TeleSpeech therapy pilot project: Stakeholder satisfaction. International Journal of Telerehabilitation, 2, 23-30. doi: 10.5195/ ijt.\%Y.6049

11. Curtis, N., Whitcomb, J., \& Wilbur, J. (2011). Speech telepractice outcomes in northern Maine. Maine: Waldo County General Hospital

12. Digital Learning Now. (nd). http://digitallearningnow.com

13. Duchan, J. (2010). Getting here: A short history of speech pathology in America. Retrieved from http:// www.acsu.buffalo.edu/ duchan/history.html

14. Gardner, H. (2011). The unschooled mind: How children think and how schools should teach. New York: Basic Books

15. Gates, B. (2010). Bill Gates talks about the Khan Academy at Aspen Ideas Festival 2010. Retrieved from http://www.khanacademy.org/talks-and-interviews/v/ bill-gates-talks-about-the-khan-academy-at-aspenideas-festival-2010

16. Go Animate. (2012). http://goanimate.com

17. Kuster, J.M. (2010). Net connections for communication disorders and sciences: An Internet guide. Retrieved from http://www.mnsu.edu/comdis/kuster2/sptherapy. html 
18. Prensky, M. (2008). Turning on the lights. Educational Leadership, 65(6), 40-45.

19. Schooling, T., Venediktov, R., \& Leech, H. (2010)

Evidence based systematic review: Effects of service delivery on the speech and language skills of children from birth to 5 years of age. Retrieved from the American Speech-Language-Hearing Association website: http:// www.asha.org/uploadedFiles/EBSR-Service-Delivery. pdf

20. Speech Techie. (2012). http://speechtechie.com

21. Toca Boca. (2012). http://tocaboca.com

22. Vygotsky, L.S. (1978). Interaction between learning and development. In M. Cole, V. John-Steiner, S.

Scribner, \& E. Souberman (Eds.), Mind and society: The development of higher psychological processes. Cambridge, Massachusetts: Harvard University 